\title{
Frequency Dependence of the $b$-Value Used for Acoustic Emission Analysis of Glass Fiber Reinforced Plastics
}

\author{
Do Yun Jung ${ }^{*}$, Yoshihiro Mizutani ${ }^{2}$, Akira Todoroki², Yoshiro Suzuki ${ }^{2}$ \\ ${ }^{1}$ Department of Mechanical Science and Engineering, Graduate School of Tokyo Institute of Technology, Tokyo, Japan \\ ${ }^{2}$ Department of Engineering, Tokyo Institute of Technology, Tokyo, Japan \\ Email: *jdoyeon@ginza.mes.titech.ac.jp
}

How to cite this paper: Jung, D.Y., Mizutani, Y., Todoroki, A. and Suzuki, Y. (2017) Frequency Dependence of the b-Value Used for Acoustic Emission Analysis of Glass Fiber Reinforced Plastics. Open Journal of Composite Materials, 7, 117-129. https://doi.org/10.4236/ojcm.2017.73007

Received: May 24, 2017

Accepted: July 3, 2017

Published: July 6, 2017

Copyright (๑) 2017 by authors and Scientific Research Publishing Inc. This work is licensed under the Creative Commons Attribution International License (CC BY 4.0).

http://creativecommons.org/licenses/by/4.0/

\section{(c) (i) Open Access}

\begin{abstract}
Acoustic Emission Testing (AT) is one of the major non-destructive testing methods used for severity evaluation of structures. Amplitude distributions of AE signals are characterized by $b$-value and the value is mainly used for the severity evaluation of concrete structures until now. The value is assumed to be independent with propagation distance between acoustic emission sources to $\mathrm{AE}$ sensors. We evaluate the influence of the wide frequency band encountered in the fracture behavior of glass fiber reinforced plastic (GFRP) on the $b$-value analysis. In tensile tests, the $b$-value was determined from an acoustic emission (AE) source generated near a centered hole in a specimen of GFRP. At $15 \mathrm{~mm}$ from the hole, the $b$-value analysis indicated a decreasing trend with increasing tensile stress. At a propagation length of $45 \mathrm{~mm}$, farthest from the hole, a small number of $\mathrm{AE}$ signals were received. The attenuation is more rapid for high-frequency $\mathrm{AE}$ signals. Thus, the amplitude distribution bandwidth is wide and the $b$-value changes. This change in $b$-value for GFRPs is investigated by analyzing the spectral components of the AE signals. For a single-frequency $\mathrm{AE}$ source, the $b$-value is unchanged with propagation length. In contrast, multiple-frequency $\mathrm{AE}$ sources produce changes in $b$-value proportional to the fraction of each spectral component in the received signal. This is due to the frequency dependence of the attenuation with propagation length. From these results, the $b$-value analysis cannot be applied to considering frequency dependence of $\mathrm{AE}$ attenuation.
\end{abstract}

\section{Keywords}

Structure Health Monitoring, $b$-Value Analysis, Acoustic Emission Testing, Fiber Reinforced Plastics, Frequency Dependence of Attenuation 


\section{Introduction}

Fiber reinforced plastics (FRPs) are becoming increasingly popular especially in industry because of their unique properties, such as excellent strength-to-weight ratio and the numerous possibilities with manufacturing components of complicated shape. The range of use is rapidly expanding into the aerospace, transport, and marine industries among others. The major drawback of FRPs is their susceptibility to impact damage [1] [2] [3] [4]. It is inevitable during the service time of FRP structures that they will be exposed to impacts from birds, flying debris, and other ballistic objects. FRPs can incur impact damage that may be barely visible including matrix cracking, de-bonding, delamination, and fiber fracture. Even though after impact there is no visible indication of low-energy impact damage on the FRP surface, four types of damage can have detrimental effect on the strength and stiffness of the mechanical and chemical structure [5] [6]. Therefore, to ensure the structural integrity of FRPs, they should be tested periodically during their service time. To date, researchers are still developing methods of evaluation to assess the structural integrity of FRPs.

The most advanced method of real-time non-destructive testing (NDT) of fracture behavior is acoustic-emission testing (AT). Traditionally, tests are based on the detection of dynamic surface motion caused by an elastic wave. AE signals are generated by a sudden release of elastically stored energy by a micro-crack and/or macro-crack during static or dynamic loading of an engineering structure [7] [8] [9] [10]. AT provides early warming and directs other NDT methods to problem areas for quantification. For this reason, AT is used as a real-time monitoring of structural health. The $b$-value analysis is one such method. The $b$-value varies with fracture evolution within the structure. Technically, in $b$-value analysis, a number of parameters are recorded from signals from which the damage state of the structure is determined. Using the $b$-value analysis, an effective damage assessment criterion is represented by the slope of the frequency distribution of the peak amplitudes from the micro-crack/macrocrack ratio [11] [12]. The $b$-value has been applied successfully to evaluate the development of fractures in a comprehensive structural integrity assessment of concrete and rock formation [13] [14] [15] [16]. The $b$-value analysis appears to be a perfect way to determine the severity of FRP structures. Furthermore, the analysis can be performed in real-time and thus enables the monitoring of damage in FRP structures using AE sources.

The amplitude of the peak voltage of a signal waveform is usually assigned. Instead of a linear scale, amplitudes are expressed on a decibel scale, where $1 \mu \mathrm{V}$ at a sensor is defined as $0 \mathrm{~dB}_{\mathrm{AE}}$. The amplitude is closely related to the magnitude of the source event. The magnitude of the amplitude in each signal has often been analyzed in relation with the frequency of the AE signal. The features of the AE signals are generally known to change with the type of fracture. Different fracture types in FRP materials generate different AE signals varying over a range of frequency and amplitude [7] [9]. Groot et al. [17] and Ramirez-Jimenez et al. [18] measured the AEs in load testing of a comprehensive series of carbon 
FRPs (CFRPs; 50 - $550 \mathrm{kHz}$ ) and glass FRP (GFRP; 80 - $520 \mathrm{kHz}$ ) and classified the detected AE signals based on their frequency spectra. Gutkin, et al. [19] [20] has studied the frequency distribution of $\mathrm{AE}$ signals recorded in several tests of various fiber stacking sequences of CFRPs using pattern recognition techniques (matrix cracking: 0 - $50 \mathrm{kHz}$, de-bonding: 200 - $300 \mathrm{kHz}$, delamination: 50 - 100 $\mathrm{kHz}$, fiber fracture: $400-500 \mathrm{kHz}$ ). These results have a wider frequency band compared with materials such as Earth's crust, rock formations, and engineering concrete [11] [12] [13] [14] [15].

The magnitude of AE peaks detected by a sensor is considerably lower than the magnitude that would have been observed near the source. This is due to wave attenuation, i.e., the lost energy of the wave through absorption and backscatter, and is described by the attenuation transfer function: $A(\omega)=A_{0}(\omega) \cdot e^{[-\alpha(\omega) \cdot d]}$, where $\alpha(\omega)$ is the frequency-dependent coefficient of attenuation and $d$ is the propagation distance [2] [20]. Higher frequencies incur higher attenuation than lower frequencies. The AE signals can indicate damage within materials but the attenuation of the AE signals may give limited details of the magnitude of the damage. Jung et al. [21] [22] had shown that the frequency dependence of the attenuation can strongly affect the distribution of the AE amplitude and $b$-value.

In this study, we evaluate the influence of the wide frequency band accompanying the fracture behavior of a FRP in $b$-value analysis. In tensile tests, the $b$-value is calculated using an $\mathrm{AE}$ source generated near the center hole and three sensors at various locations to detect the propagating signals. In addition, the attenuation was measured using the results of tensile tests We then performed a numerical simulation using an AE source of $45 \mathrm{~mm}$ propagation length to determine the effect of an $\mathrm{AE}$ component on the $b$-value analysis.

\section{Analysis of $b$-Value}

By accumulating distribution data of the frequency and magnitude, the $b$-value can be calculated by applying the Gutenberg-Richter relation [13]. Widely used in earthquake seismology, this equation takes the empirical form

$$
\log _{10} N(M)=a-b M
$$

with

$$
N(M)=\int_{M}^{\infty} n(M) d M
$$

where $M$ is the magnitude of an earthquake, $n(M)$ the number of earthquakes of magnitude $M, N(M)$ the total number larger than magnitude $\mathrm{M}$, and a and $\mathrm{b}$ is empirical constants. As seen in Equation (2), the magnitude is proportional to the logarithm of the maximum amplitude $\left(\log _{10} N\right)$. From Equations (1) and (2), the $b$-value is the negative gradient of the log-linear plot of AE events and magnitude and therefore it represents the slope of the amplitude distribution (see Figure 1). For the AE technique, the Gutenberg-Richer formula is modified to

$$
\log _{10} N=a-b\left(\frac{d B_{A E}}{20}\right)
$$




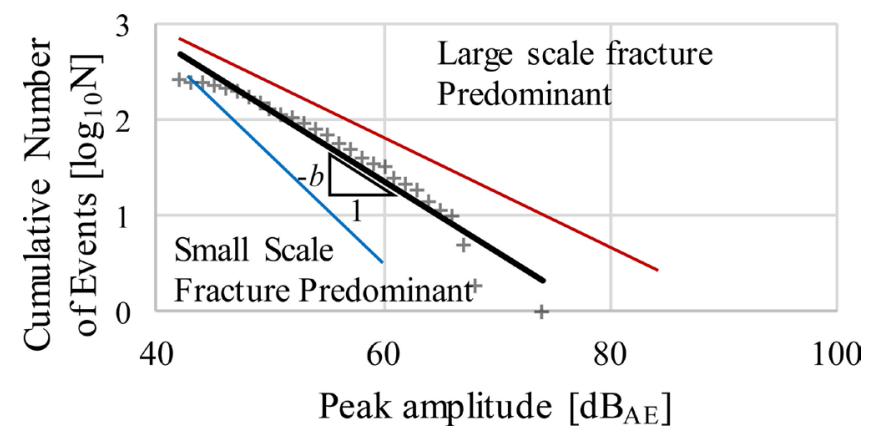

Figure 1. Definition of $b$-value for the modified Gutenberg-Richer formula.

Micro-cracks with small AE amplitudes yield high $b$-value whereas macro-cracks with large amplitudes produce relatively low values. When the level of damage of structures approaches final fracture, the fracture behavior changes from micro cracking to macro-cracking for which then $b$-value becomes small [13] [14] [15] [16].

\section{Change of AE Parameter with Propagation Length}

In general, the decrease in the amplitude of the AE signals in plates resulting from attenuation with propagation length $\mathrm{r}$ can be expressed as

$$
A(\omega, r)=A_{0}(\omega) \cdot \frac{1}{\sqrt{r}} \cdot \exp [-\alpha(\omega) \cdot r]
$$

Here, $A_{1}$ is the amplitude of the cylindrical waves at propagation distance $\mathrm{r}$ from the source and $\alpha$ the frequency of the wave. The amplitude at the source is denoted $A_{o}$ and $A_{1} / A_{o}$ is the attenuation ratio. The relationship between $d B_{A E}$ and propagation distance $r$ is derived from Equation (4)

$$
d B_{A E}=20 \cdot \log _{10}\left\{\frac{1}{\sqrt{r}} \cdot \exp [-\alpha(\omega) \cdot r]\right\}
$$

\section{4. $b$-Value Distribution under Tensile Test}

The first experiment chosen for the $b$-value is a test from a series of tensile tests of GFRP under axial load. The GFRP specimens used have dimension $220^{\mathrm{L}} \times$ $40^{\mathrm{W}} \times 2.5^{\mathrm{t}}$ with a centered hole $\left(6 \mathrm{~mm}^{\varnothing}\right)$. The $b$-value analysis must be conducted with AE signals recorded at certain locations (sources). When damage occurs at various locations in a structure, the $\mathrm{AE}$ source location must be established and the $b$-value analysis must be conducted separately for the $\mathrm{AE}$ signals from each source. In this study, the centered hole was introduced as a single source location, however then source location was not established before the $b$-value analysis. The specimens contain woven glass fiber (fiber volume contest: $52.3 \%$ ). For the tensile test, 2-mm-thick GFRP tabs were attached to each specimen at both ends to avoid causing any damage from the jig. Four AE sensors (Physical Acoustics, Type: PICO) were mounted on each specimen at fixed distances from the hole (labeled S1-S5 in Figure 2; S4 and S5 are guard sensors). The cross-head speed of the tensile tester was controlled at $0.1 \mathrm{~mm} / \mathrm{min}$. With the concentration 

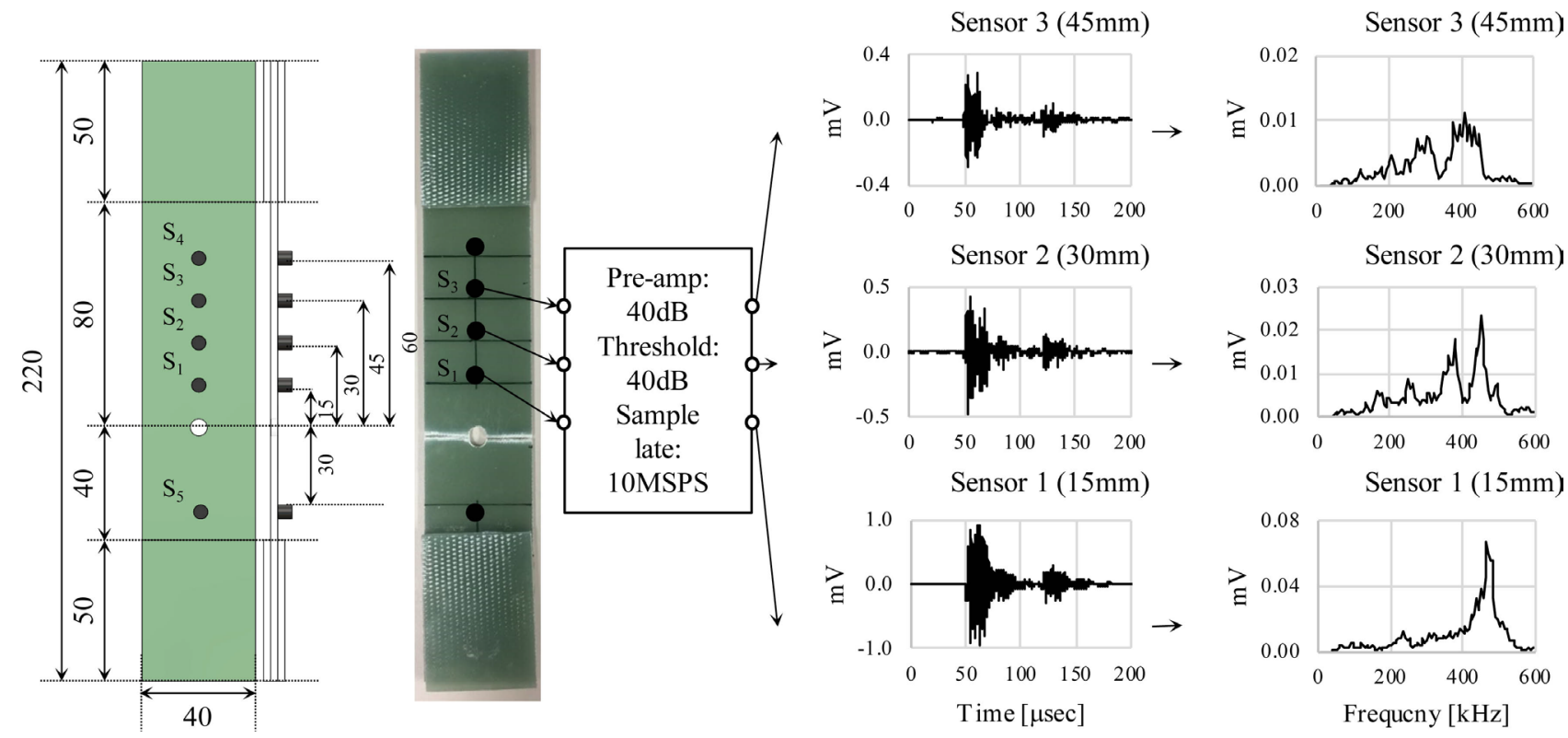

Figure 2. (Left) Sketch of a woven GFRP specimen with a centered hole and five sensors; (Right) Recorded acoustic emission signals from tensile testing. The source was between sensor 1 and sensor 3. From the concentration of stress, the specimen broke near the centered hole. The frequency spectrum is obtained using AE analysis software (Vallen System, Type: Visual AE) performing a fast Fourier analysis.

of stress, specimens break near the centered hole. Therefore, four AE sources were evenly distributed around this area on the surface of the tensile specimens. During each test, $\mathrm{AE}$ signals larger than $40 \mathrm{~dB}_{\mathrm{AE}}$ were detected using a digitizer (Physical Acoustics, Type: PCI-2) at a sampling rate of $10 \mathrm{MHz}$ per channel.

Figure 3 shows amplitude of AE (Figure 3(a)) and cumulative AE hits (Figure 3(b)) during the test with time history of stress is over wrapped to the figure. As show in the Figure 3, peak amplitude of $\mathrm{AE}$ and cumulative hits increased with stress. Figure 4 shows the distribution of the frequency centroid with different propagation length. The frequency centroid is calculated using the AE analysis software (Vallen system, Type: Visual AE), which employs the fast Fourier transform method. The frequency centroid is an important parameter for characterizing the frequency dependence of the attenuation. Here three bands of frequencies are evident from the tensile test data. The results of the frequency centroid distribution were grouped according to propagation length (d): $\mathrm{d}=15 \mathrm{~mm}$ corresponds to the range $75-525 \mathrm{kHz} . \mathrm{D}=30 \mathrm{~mm}$ to range 90 $490 \mathrm{kHz}$, and $\mathrm{d}=45 \mathrm{~mm}$ to range $90-480 \mathrm{kHz}$. A wide band for the frequency centroid (sensor 1, $75-525 \mathrm{kHz}$ ) signifies a distinct type of damage related to failure modes that arise near the center hole in the GFRP specimen. However, obtaining information about the amplitude and number of events from the $\mathrm{AE}$ signals is limited because of their propagation.

The results for the $b$-value under axial loading are presented in Figure 5. The $\mathrm{AE}$ data from axial loading were divided by 1000 units and the time evolution of the distributions are shown after a standard analysis of the variance in order to perform a $b$-value analysis. The results are given in a plot of $b$-values (black double line) along with the stress (red line, $\Delta$ ). They indicate a sharp change in 


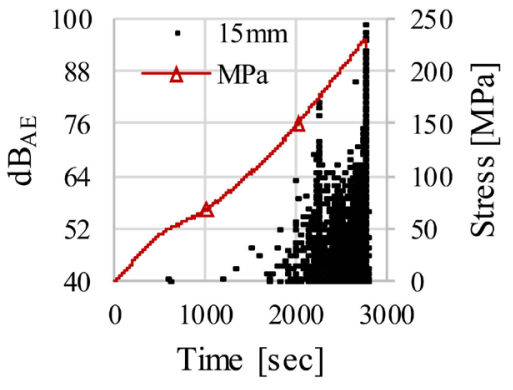

(a)

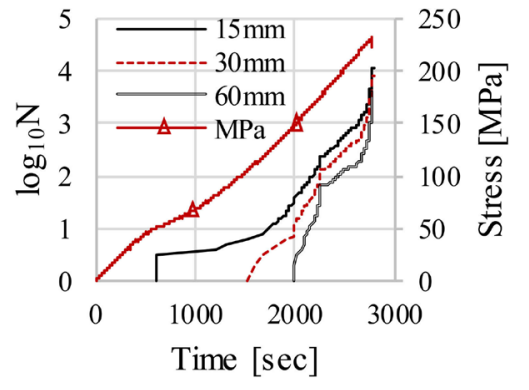

(b)

Figure 3. Time evolution of (a) AE signal peak amplitude vs. stress and (b) log-linear plot of the cumulative events vs. stress.

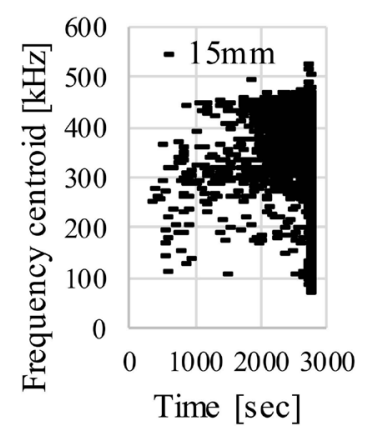

(a)

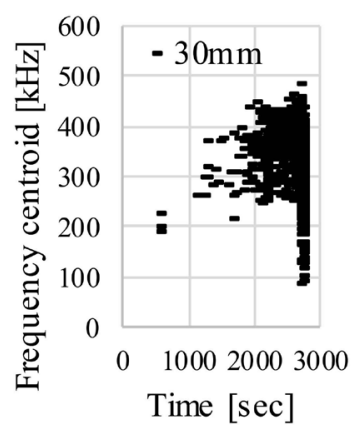

(b)

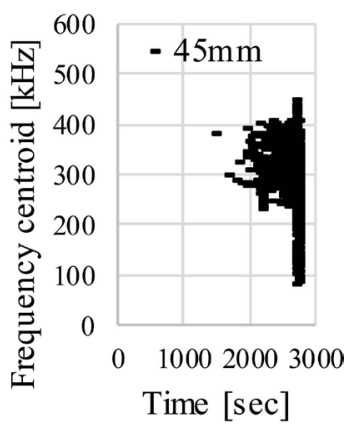

(c)

Figure 4. Time evolution of the frequency centroid for the detected AE signals for various propagation lengths. (a) Propagation: $15 \mathrm{~mm}$; (b) Propagation: $30 \mathrm{~mm}$; (c) Propagation: $45 \mathrm{~mm}$.

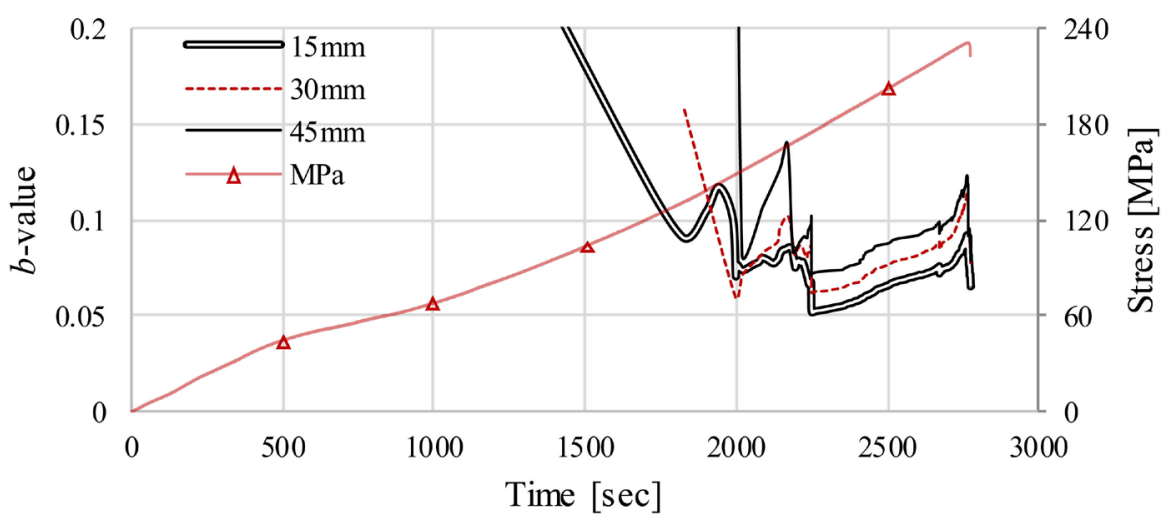

Figure 5. Time dependence of the $b$-value and uniaxial tensile stress for various propagation lengths.

$b$-value with increasing stress, which are marked in the plots and displayed in Figure 5 . The $b$-value decreases on reaching $74 \%$ of the failure stress attaining a value of about 0.05 . Thereafter, the $b$-value increases. However, its value falls rapidly when catastrophic failure occurs. The $b$-value is correctly even with the increase in GFRP stress. However, as seen in Figure 5, the $b$-value variation with propagation length increases. The rate of change shown in sensor 3 (propagation length $45 \mathrm{~mm}$, black line) is larger than that of sensor 2 (propagation length 30 $\mathrm{mm}$, red dotted line). To investigate the cause of this change with increasing propagation length, the amplitude distribution of the AE with different fre- 
quency centroids was investigated.

In general, the frequency centroid of the $\mathrm{AE}$ signals generated from the $\mathrm{AE}$ source in engineering structures may vary over some range. The range becomes wider when assuming composite materials made of different materials like FRPs. Figure 6(a) and Figure 6(b) shows the cumulative amplitude distributions for the $\mathrm{AE}$ signals with frequency centroids in the range 75 to $525 \mathrm{kHz}$ taken at different times. The results of the distribution for propagation lengths of $15 \mathrm{~mm}$ are indicated by open circles, $30 \mathrm{~mm}$ by open triangles, and $45 \mathrm{~mm}$ by open boxes. The slope of each line ( $b$-value) is measured by a linear fit to the data. The results give the $b$-value of the frequency centroid for each $\mathrm{AE}$ source and varies from $0.66(0.09)$ to $0.88(0.122)$ as the propagation length increases from 15 to 45 $\mathrm{mm}$.

The frequency dependence of the attenuation is shown in Figure 7 During tensile testing, we recorded AE signals with different frequency centroids, specifically, 237, 309, 348, 402 and $469 \mathrm{kHz}$, at sensor $1(\mathrm{~d}=15 \mathrm{~mm})$. The AE source group velocity was determined based on the arrival times at sensors $1,2(d=30$ $\mathrm{mm})$, and $3(\mathrm{~d}=45 \mathrm{~mm})$. The AE signals have an amplitude of $3500 \mathrm{mV}$ at $\mathrm{d}=$ $15 \mathrm{~mm}$. All amplitudes decreased with increasing propagation length. Moreover, higher-frequency AE signals incur higher attenuation than those of lower frequency. To investigate the cause of the change in the amplitude distribution, the dependence of the attenuation with frequency centroid was investigated.

From the distribution of the frequency centroid (Figure 8), three frequency

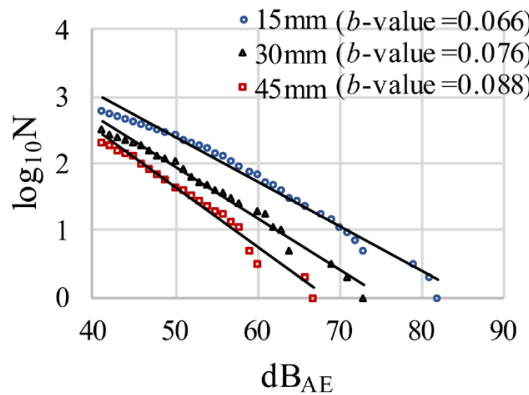

(a)

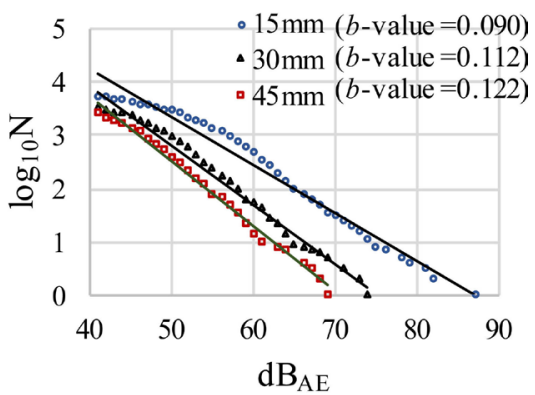

(b)

Figure 6. Plots of cumulative events $v s$ amplitude and $b$-value for all tensile tests spanning time intervals 0 - 2500 and 0 - 2760 s. (a) Time interval: 0 - 2500 s; (b) Time interval: 0 - $2760 \mathrm{~s}$.

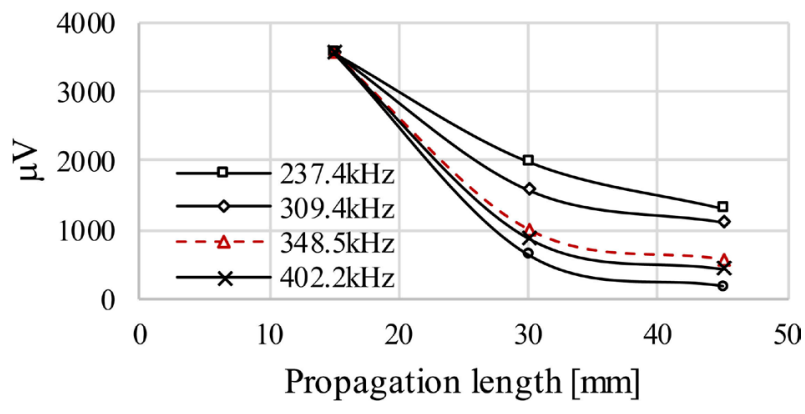

Figure 7. Dependence of AE amplitude on AE sensor location for various frequency centroid between 237 and $469 \mathrm{kHz}$. 


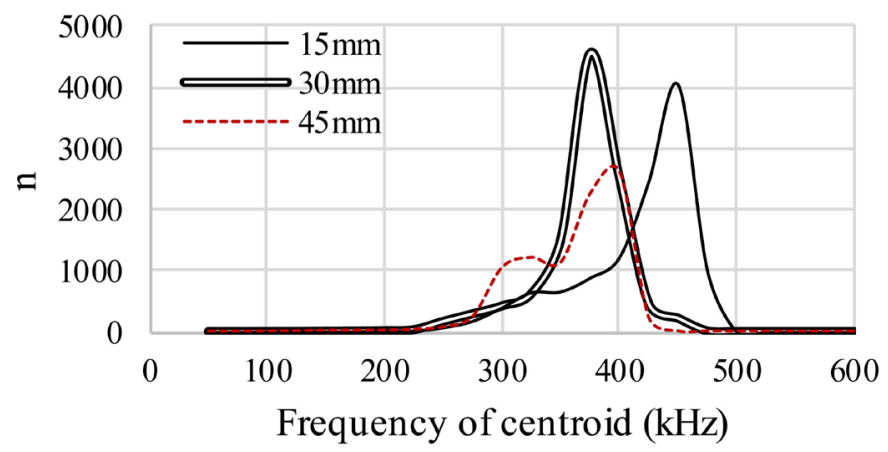

Figure 8. Frequency distribution of sensor 1, sensor 2 and sensor 3 at final fracture (all AE sources).

bands are evident in the data from all tensile tests. The results of the distribution are separated by propagation length: a black line marks those for $\mathrm{d}=15 \mathrm{~mm}$, a double line marks those for $\mathrm{d}=30 \mathrm{~mm}$, and a red dotted line for those of $\mathrm{d}=45$ $\mathrm{mm}$. The central frequencies are $440 \mathrm{kHz}$ for $\mathrm{d}=15 \mathrm{~mm}, 380 \mathrm{kHz}$ for $\mathrm{d}=30$ $\mathrm{mm}$, and $320 \mathrm{kHz}$ and $390 \mathrm{kHz}$ for $\mathrm{d}=45 \mathrm{~mm}$. As show in the figure, the frequency centroid and the distribution of the number of events are shifted as propagation length increases with frequency dependence of attenuation.

\section{Numerical Simulations for Various Propagation-Length Settings}

To investigate changes in $b$-value by the fractional contribution to AE in GFRP, numerical simulation was performed to estimate the $b$-value under changes in frequency centroid and propagation length. Materials undergoing failure produce a large number of AEs with various amplitudes and various frequencies. Figure 9(a) shows the results of $b$-value analysis for data recorded at sensor 3 (d $=45 \mathrm{~mm}$ ) which was used as the source in the numerical simulation. We ran $8558 \mathrm{AE}$ events with various amplitudes and cumulative number of events (Figure 9(b)). Through the reverse-design method, with the $b$-value becoming the experimental result, the frequency centroid at the source is then controlled (Figure $9(\mathrm{c})$ ). We confirmed the dominant frequencies for each fracture mode. The AE contribution from each fracture mode created in the GFRP was separated using band-pass frequency filters for the ranges $50-320 \mathrm{kHz}$ (source $\mathrm{A}$, number of events: 2651), $320-380 \mathrm{kHz}$ (source B, number of events: 3041), and $380-480 \mathrm{kHz}$ (source C, number of events: 2866). Figure 10(a) and Figure 10 (b) shows the propagation parameter in the simulation. From Figure 10(a), the attenuation factors can be estimated based on the tensile test data (see Figure 7, Equation (4)); they are $0.003,0.012,0.033$, and $0.011 \mathrm{~Np} / \mathrm{mm}$, respectively. Hence the amplitude at the source which is given in $\mathrm{dB}_{\mathrm{AE}}$ decreases with increasing propagation length (Figure 10(b)). We conducted the simulation subject to one of two conditions, one being that the $\mathrm{AE}$ source contains the same multiple frequencies of 170,355 , and $485 \mathrm{kHz}$ and the other being that the $\mathrm{AE}$ source contains only a single frequency of $366 \mathrm{kHz}$. The attenuation of the AE signals was calculated using Equation (5). 


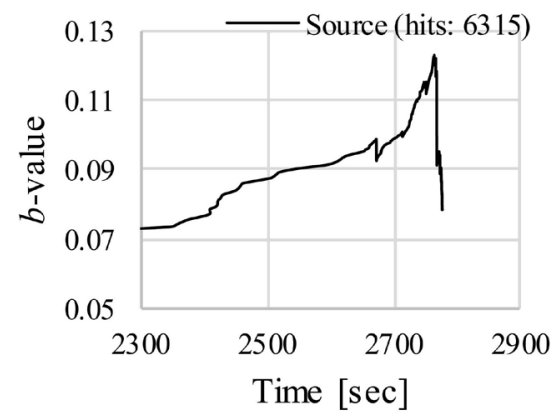

(a)

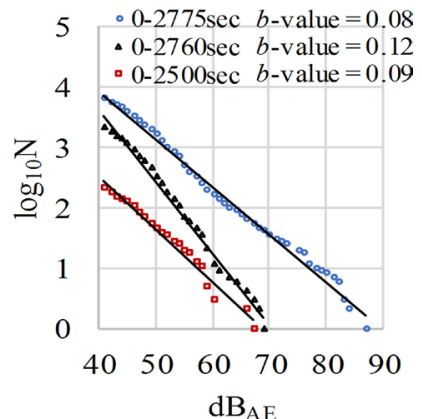

(b)

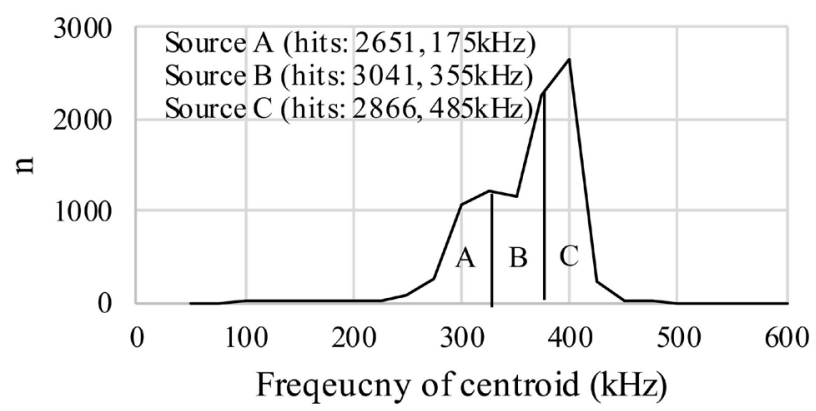

(c)

Figure 9. Numerical simulation source. (a) Amplitude vs. stress; (b) Cumulative events vs. stress; (c) Contribution for each simulation source.

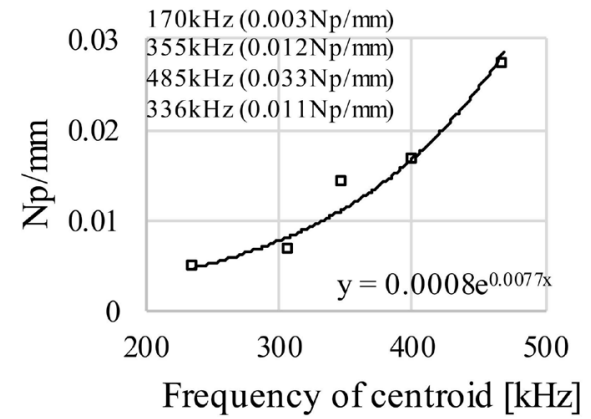

(a)

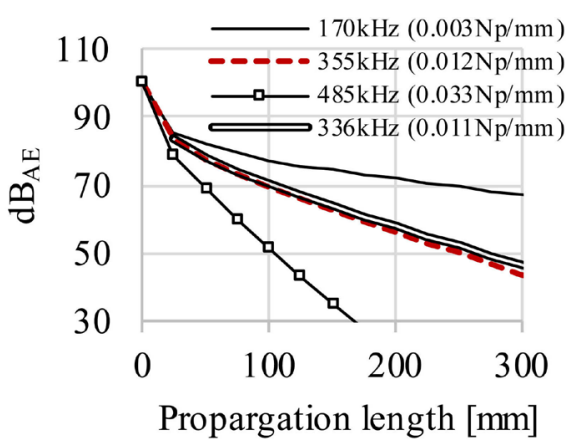

(b)

Figure 10. Cumulative AE amplitude for multiple AE sources (b) when the frequency dependence of attenuation (a). (a) Attenuation parameter; (b) Amplitude vs. propagation length.

Figure 11 shows the final simulation results for a single frequency (Figure 11(a)) and multiple frequencies (Figure 11(b)) for the different propagation lengths. The $b$-value was calculated for each point ( $2300-2780 \mathrm{~s} / 1000$ points) using the least squares method. As shown in the figure, the $b$-value of the single-frequency source does not change with propagation length; in contrast, a change occurs for the multiple-frequency source. The $b$-values for both propagation conditions fluctuated over some range during the test, although the average of the $b$-values for the specimen with propagation length $125 \mathrm{~mm}$ is lower than that of the source. From these results, the change in $b$-value may be caused by a change in the frequency dependence of the attenuation after propagation.

Figure 12 shows the cumulative amplitude distributions obtained from nu- 
merical simulations for which the $\mathrm{AE}$ signal and frequency originate from Source A $(50-320 \mathrm{kHz})$, Source B $(320-380)$, and Source C $(380-480 \mathrm{kHz})$. The results for the distributions corresponding to the sources are grouped by propagation length: “ $\bigcirc$ ” for $\mathrm{d}=45 \mathrm{~mm}$, " $\square$ ” for $\mathrm{d}=85 \mathrm{~mm}$, and “-” for $\mathrm{d}=$ $125 \mathrm{~mm}$. Figure 12(a) and Figure 12(b) shows the simulation results for a single frequency and multiple frequencies, respectively, for the different propagation lengths. From the figure, the $b$-value of the single-frequency source does not change with propagation length, whereas it decreases for multiple-frequency sources with increasing propagation length. The $b$-values for both propagation conditions fluctuated during the test over some range. Moreover, the average of the $b$-value for the results for propagation length $125 \mathrm{~mm}$ is lower than that of the source.

Figure 13 shows the simulation results for (a) single frequency and (b) mul-

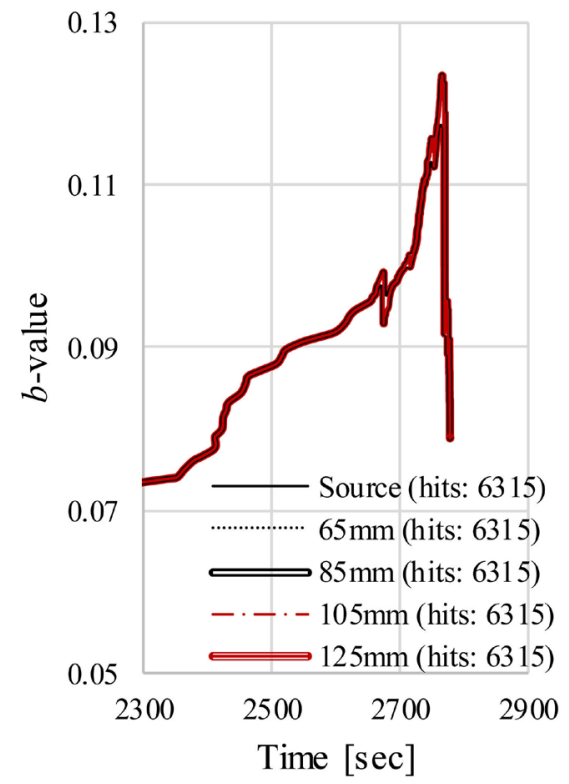

(a)

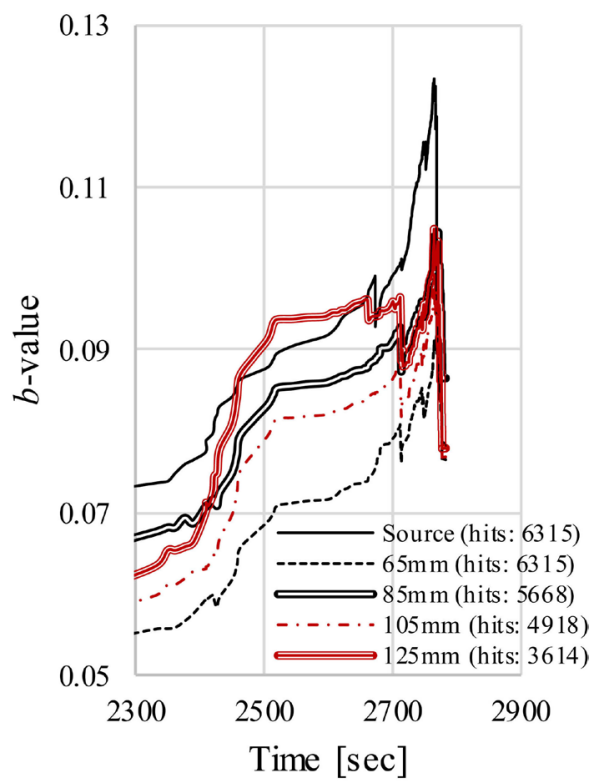

(b)

Figure 11. Relationship between (a) single-frequency and (b) multiple-frequency $b$-value displacements propagation length sources (45 mm), 65, 85, 105, and $125 \mathrm{~mm}$.

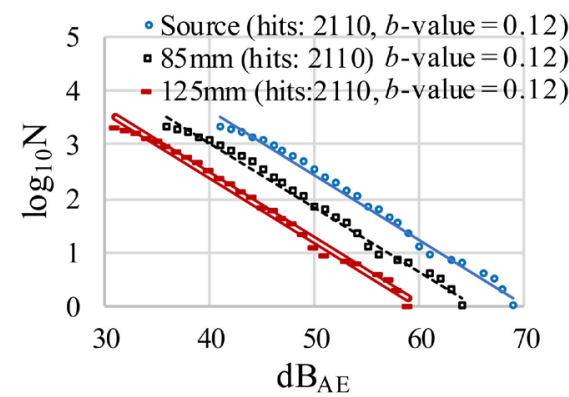

(a)

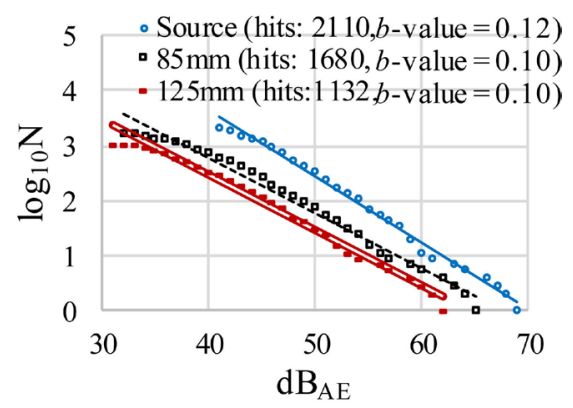

(b)

Figure 12. Amplitude frequency distributions of the AE signals at $1920 \mathrm{~s}$ with single frequency (a) and multiple frequencies (b). The distributions at the sources with propagation lengths $85 \mathrm{~mm}$ and $125 \mathrm{~mm}$ are also delayed. (a) Single frequency (0 - $2760 \mathrm{~s})$; (b) Multiple frequency (0 - $2760 \mathrm{~s})$. 


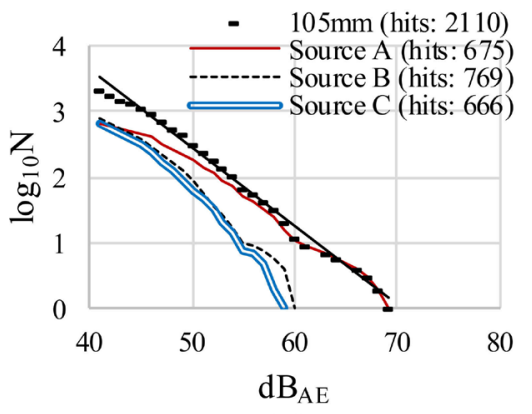

(a)

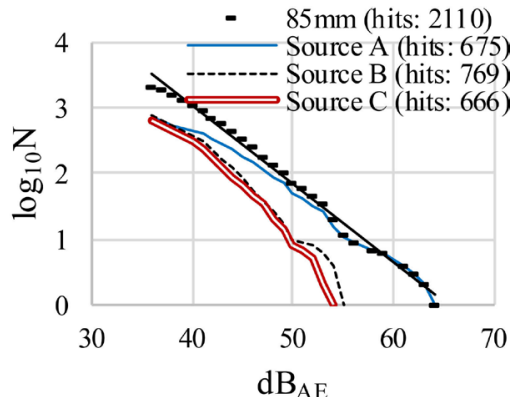

(b)

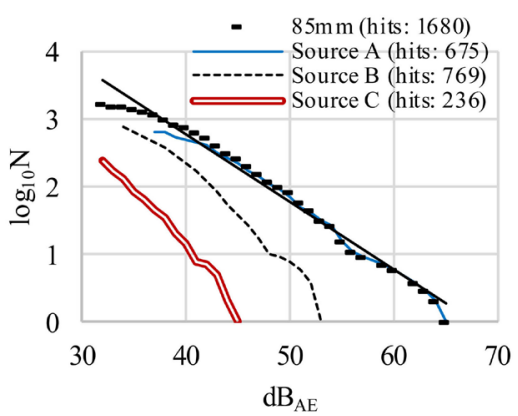

(c)

Figure 13. Proportion of the amplitude of the AE signals at the various sources and 85 $\mathrm{mm}$ from the central hole. The single-frequency (b) and multiple-frequency (c) distributions (black line) are also presented for sources A, B, and C. (a) Source (45 mm, $0-2760$ s); (b) Single frequency (0 - $2760 \mathrm{~s})$; (c) Multiple frequency (0 - $2760 \mathrm{~s})$.

tiple frequencies with Source A (50 - $320 \mathrm{kHz})$, Source B (320 - 380), and Source $\mathrm{C}(380-480 \mathrm{kHz})$. The results of the distribution with Source A are indicated by blue solid lines, Source B by black dotted lines, Source C by red double-solid lines, and the total source by black dashed lines. The $b$-values were calculated for each condition using the total AE source. As shown in the figure, the contribution to the total $\mathrm{AE}$ source for a single-frequency source does not change by changing the propagation length. However, for the multiple-frequency source, the contribution changes with increasing propagation length. Because of the difference in the attenuation factor resulting from the frequency dependence, the amplitude distributions for single frequencies 150,250 , and $500 \mathrm{kHz}$ were separated for propagation length $\mathrm{d}=110 \mathrm{~mm}$. The slope of the distribution ( $b$-value) for the multiple-frequency source at higher amplitudes is affected only for Source A. For the same reason, the middle region of the distribution is mainly affected by Source B and the lower region by Source C. Finally, the $b$-value decreases from $\mathrm{A}$ to $\mathrm{B}$ with the corresponding increase in propagation length. From these results, the change in $b$-value may be caused by a change in the contribution of each frequency component following propagation through the frequency dependence of the attenuation.

\section{Conclusions}

In this study, effect of propagation distance of AE in FRPs on $b$-value was investigated. The different failure mechanisms, matrix cracking, de-bonding, delami- 
nation, fiber fracture generate AEs with a different frequency range. We analyzed the $b$-value using three sensors with different propagation distance from AE source. Followings are summarized of this pager;

1) In FRPs, $b$-value is changed with propagation distance, not like concrete structures.

2) When the $\mathrm{AE}$ source contained a single frequency, component, the $b$-value does not change with propagation distance. In construct, when the AE source contained multiple frequencies, changes in $b$-value occur that may be caused frequency dependence of AE attenuation.

\section{Acknowledgements}

This work was supported by JSPS KAKENHI Grant Number 16J12078.

\section{References}

[1] Diamanti, K. and Soutis, C. (2010) Structural Health Monitoring Techniques for Aircraft Composite Structures. Progress in Aerospace Sciences, 46, 342-352. https://doi.org/10.1016/j.paerosci.2010.05.001

[2] Coverley, P.T. and Staszewski, W.J. (2003) Impact Damage Location in composite Structures Using Optimized Sensor. Smart Materials and Structures, 12, 795-803. https://doi.org/10.1088/0964-1726/12/5/017

[3] Found, M.S. (1998) Impact Behaviour of FRP Composites. Key Engineering Materials, 144, 55-62. https://doi.org/10.4028/www.scientific.net/KEM.144.55

[4] Seltzer, R., González, C., Muñoz, R., Llorca, J. and Blanco-Varela, T. (2013) X-Ray Microtomography Analysis of the Damage Micromechanisms in 3D Woven Composites under Low-Velocity Impact. Applied Science and Manufacturing, 45, 49-60. https://doi.org/10.1016/j.compositesa.2012.09.017

[5] Parga-Landa, B. and Hernández-Olivares, F. (1995) An Analytical Model to Predict Impact Behaviour of Soft Armours. International Journal of Impact Engineering, 16, 455-466. https://doi.org/10.1016/0734-743X(94)00054-Z

[6] Wu, Q.G., Wen, H.M., Qin, Y. and Xin, S.H. (2012) Perforation of FRP Laminates under Impact by Flat-Nosed Projectiles. Composites Part B: Engineering, 43, 221 227. https://doi.org/10.1016/j.compositesb.2011.08.045

[7] Grosse, C.U. (2008) Acoustic Emission Testing. Springer, Berlin. https://doi.org/10.1007/978-3-540-69972-9

[8] Mizutani, Y., Nagashima, K., Takemoto, M. and Ono, K. (2000) Fracture Mechanism Characterization of Cross-Ply Carbonfiber Composites Using Acoustic Emission Analysis. NDT \& E International, 33, 101-110. https://doi.org/10.1016/S0963-8695(99)00030-4

[9] Hull, R., Chennupati, J., Kawazoe, Y., Osgood, R.M. and Jparisi, U. (2016). In Situ Monitoring of Composites. Springer International Publishing, Berlin.

[10] Kessler, S.S., Spearing, S.M. and Soutis, C. (2002) Damage Detection in Composite Materials Using Lamb Wave Methods. Smart Materials and Structures, 11, 269-278. https://doi.org/10.1088/0964-1726/11/2/310

[11] Colombo, I.S., Main, I.G. and Forde, M.C. (2003) Assessing Damage of Reinforced Concrete Beam Using “ $b$-Value” Analysis of Acoustic Emission Signals. Journal of Materials in Civil Engineering, 15, 280-286. https://doi.org/10.1061/(ASCE)0899-1561(2003)15:3(280) 
[12] Shiotani, T., Fujii, K., Aoki, T. and Amou, K. (1994) Evaluation of Progressive Failure Using AE Sources/Improved b-Value on Slope Model Tests. Progress in Acoustic Emission, 7, 529-534.

[13] Gutenberg, B. and Richter, C.F. (2010) Magnitude and Energy of Earthquakes. Annals of Geophysics, 53, 7-12.

[14] Rao, M.V.M.S. and Lakshmi, K.J.P. (2005) Analysis of $b$-Value and Improved $b$-Value of Acoustic Emissions Accompanying Rock Fracture. Current Science, 89, 1577-1582.

[15] Sagar, R.V., Prasad, B.K.R. and Kumar, S.S. (2012) An Experimental Study on Cracking Evolution in Concrete and Cement Mortar by the b-Value Analysis of Acoustic Emission Technique. Cement and Concrete Research, 42, 1094-1104. https://doi.org/10.1016/j.cemconres.2012.05.003

[16] Zitto, M.E., Piotrkowski, R., Gallego, A., Sagasta, F. and Benavent-Climent, A. (2015) Damage Assessed by Wavelet Scale Bands and $b$-Value in Dynamical Tests of a Reinforced Concrete Slab Monitored with Acoustic Emission. Mechanical Systems and Signal Processing, 60, 75-89. https://doi.org/10.1016/j.ymssp.2015.02.006

[17] de Groot, P.J., Wijnen, P.A.M. and Janssen, R.B.F. (1995) Real-Time Frequency Determination of Acoustic Emission for Different Fracture Mechanisms in Carbon/Epoxy Composites. Composites Science and Technology, 55, 405-412. https://doi.org/10.1016/0266-3538(95)00121-2

[18] Ramirez-Jimenez, C.R., Papadakis, N., Reynolds, N., Gan, T.H., Purnell, P. and Pharaoh, M. (2004) Identification of Failure Modes in Glass/Polypropylene Composites by Means of the Primary Frequency Content of the Acoustic Emission Event. Composites Science and Technology, 64, 1819-1827.

https://doi.org/10.1016/j.compscitech.2004.01.008

[19] Gutkin, R., Green, C.J., Vangrattanachai, S., Pinho, S.T., Robinson, P. and Curtis, P.T. (2011) On Acoustic Emission for Failure Investigation in CFRP: Pattern Recognition and Peak Frequency Analyses. Mechanical Systems and Signal Processing, 25, 1393-1407. https://doi.org/10.1016/j.ymssp.2010.11.014

[20] Hafizi, Z.M., Epaarachchi, J. and Lau, K.T. (2013) An Investigation of Acoustic Emission Signal Attenuation for Monitoring of Progressive Failure in Fiberglass Reinforced Composite Laminates. International Journal of Automotive and $\mathrm{Me}$ chanical Engineering, 8, 1442-1456. https://doi.org/10.15282/ijame.8.2013.31.0119

[21] Jung, D., Mizutani, Y., Todoroki, A. and Suzuki, Y. (2016) Change in $b$-Value by AE Propagation Length in Cfrp. Journal of Acoustic Emission, 33, 123-129.

[22] Jung, D., Mizutani, Y., Todoroki, A. and Suzuki, Y. (2015) A Study of the Change in $b$-Value by AE Propagation Length. The 20 th Acoustic Emission Conference, Nagoya, 19-20 November, 197-202. 
Submit or recommend next manuscript to SCIRP and we will provide best service for you:

Accepting pre-submission inquiries through Email, Facebook, LinkedIn, Twitter, etc. A wide selection of journals (inclusive of 9 subjects, more than 200 journals)

Providing 24-hour high-quality service

User-friendly online submission system

Fair and swift peer-review system

Efficient typesetting and proofreading procedure

Display of the result of downloads and visits, as well as the number of cited articles Maximum dissemination of your research work

Submit your manuscript at: http://papersubmission.scirp.org/

Or contact ojcm@scirp.org 